Document downloaded from:

http://hdl.handle.net/10251/81077

This paper must be cited as:

Desantes Fernández, JM.; García Oliver, JM.; Vera-Tudela-Fajardo, WM.; López Pintor, D.; Schneider, B.; Boulouchos, K. (2016). Study of the auto-ignition phenomenon of PRFs under $\mathrm{HCCl}$ conditions in a RCEM by means of spectroscopy. Applied Energy. 179:389-400. doi:10.1016/j.apenergy.2016.06.134.

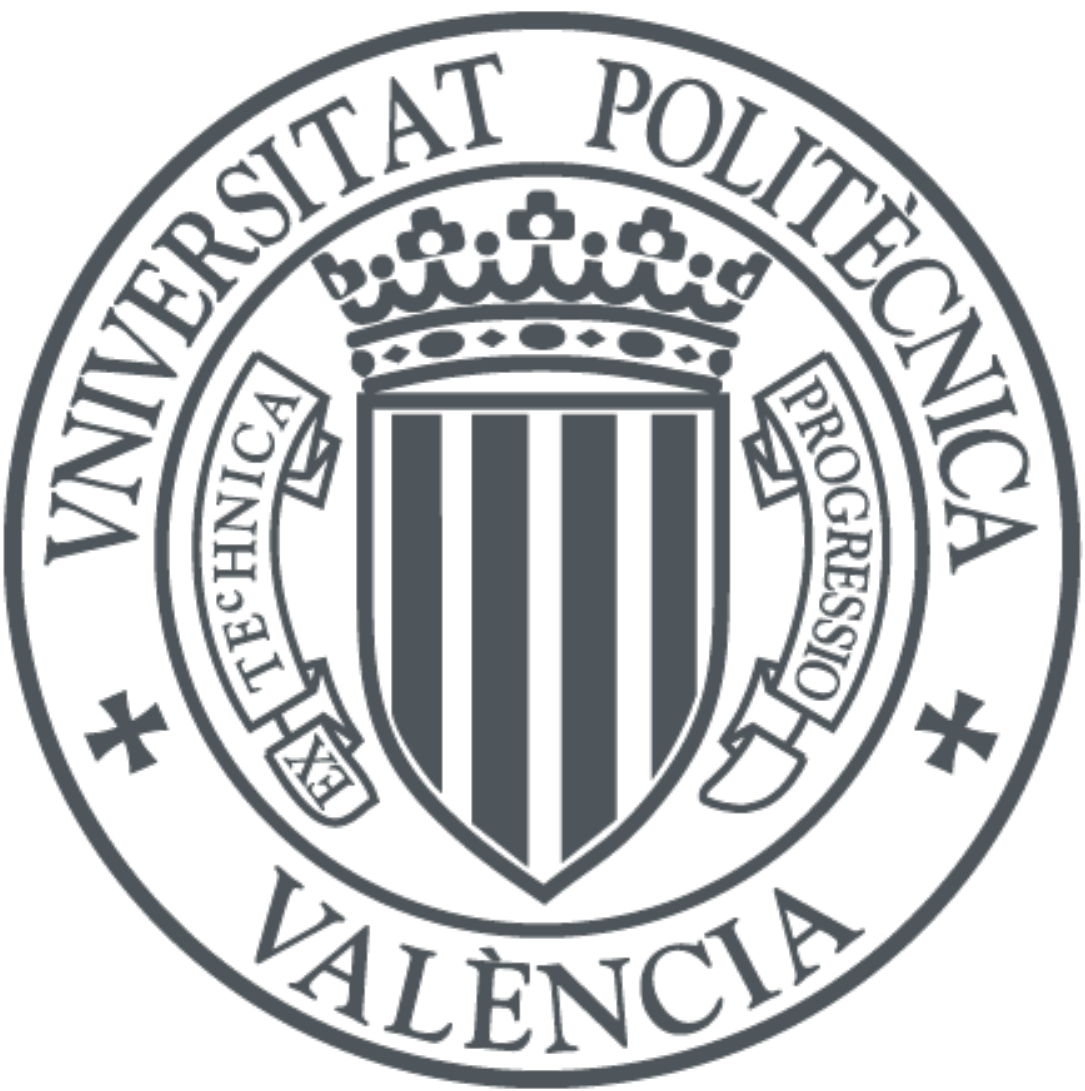

The final publication is available at

http://dx.doi.org/10.1016/j.apenergy.2016.06.134

Copyright Elsevier

Additional Information 


\title{
Study of the auto-ignition phenomenon of PRFs under HCCI conditions in a RCEM by means of spectroscopy
}

\author{
J.M. Desantes ${ }^{a}$, J.M. García-Oliver ${ }^{a}$, W. Vera-Tudela ${ }^{a, b, *}$, \\ D. López-Pintor ${ }^{\mathrm{a}, \mathrm{b}, *}$, B. Schneider ${ }^{\mathrm{b}}, \mathrm{K}$. Boulouchos ${ }^{\mathrm{b}}$ \\ ${ }^{a}$ CMT-Motores Térmicos \\ Universitat Politècnica de València \\ Camino de Vera, $s / n$. 46022 Valencia, SPAIN \\ ${ }^{b}$ Laboratorium für Aerothermochemie und Verbrennungssysteme \\ Eidgeössiche Technische Hochschule Zürich \\ Sonneggstrasse 3,CH-8092 Zürich, SWITZERLAND
}

\begin{abstract}
An investigation of the effects of contour conditions and fuel properties on the auto-ignition and combustion process under HCCI conditions is presented in this study. A parametric variation of initial temperature, intake pressure, compression ratio, oxygen concentration and equivalence ratio has been carried out for Primary Reference Fuels in a Rapid Compression Expansion Machine while applying spectroscopy. The results have also been contrasted with natural chemiluminescence measurements. Additionally, the experiments have been simulated in CHEMKIN and the results derived from the optical techniques have been compared with the results from the chemical kinetics of the process, validating the chemical kinetic mechanism and an additional sub-model of excited $O H^{*}$. Two different scenarios can be seen according to the results from the spectrograph. For very lean or very low-
\end{abstract}

\footnotetext{
*Corresponding author

Tel: $\quad+34963879$ 232. $\quad$ Fax: $\quad+34963877$ 659. $\quad$ E-mail: walvetu@mot.upv.es dalopin1@mot.upv.es
} 
temperature combustions no peak of $O H^{*}$ is seen at $310 \mathrm{~nm}$ of wavelength, proving that the luminosity came from the $C O$ continuum rather than from the $O H^{*}$. However, for more intense combustions (richer equivalence ratios, higher temperatures or lower EGR rates) spectrography shows a clear peak of $O H^{*}$ that has much longer time of life than the corresponding to the $\mathrm{CO}$ continuum. The main chemical reaction that causes this two scenarios has been identified as $\mathrm{H}+\mathrm{HO}_{2} \Rightarrow 2 \mathrm{OH}$. The increase of relevance of this reaction at high combustion temperatures causes a higher $O H^{*}$ accumulation, which leads to a brighter $O H^{*}$ emission. Finally, for low temperature combustions the $C O$ continuum out-shines the $O H^{*}$ radiation so the light emitted by this radical cannot be detected by means of natural chemiluminescence.

Keywords: RCEM, spectroscopy, PRF, chemiluminescence

\section{Introduction}

Homogeneous Charge Compression Ignition (HCCI), Premixed Charge Compression Ignition (PCCI) and other advanced engine combustion modes based on Low Temperature Combustion (LTC), have been studied in the last years as ways to simultaneously reduce soot and $N O_{x}$ emissions in Compression Ignition (CI) engines [1, 2]. These modes manage to accomplish such task; however, high emissions of unburned hydrocarbons (UHC) and carbon monoxide $(\mathrm{CO})$ are achieved. The reduction of soot and $N O_{x}$ are reached by avoiding their formation peninsulas, which can be seen in equivalence ratio temperature diagrams [3]. UHC and $C O$ can be easily oxidized with the current post-treatment systems. Thus, the main challenge to implement these new combustion strategies in commercial reciprocating internal combustion 
engines is the lack of control over the autoignition process and over the heat release rate [4].

The ignition control is much more difficult under these conditions; however, by adjusting engine operating parameters like the Exhaust Gas Recirculation (EGR) rate or the inlet temperature, the chemical kinetics of the charge can be controlled [5]. Therefore, it is necessary to improve the knowledge about the autoignition phenomenon and about the combustion process under low temperature conditions to properly modify the operating conditions of the engine and control the heat release and, therefore, the combustion efficiency.

Spectroscopy is a non-intrusive optical technique widely used in combustion diagnosis [6], such optical techniques are powerful tools to analyze not only the ignition of homogeneous mixtures, but also different parameters of the combustion process. Natural luminosity analysis and spectroscopy have shown to be able to describe the different phases of the combustion process under HCCI conditions [7].

Mancaruso and Vaglieco [8] applied spectroscopic measurements to a transparent diesel engine in order to study the low temperature combustion process. They saw that the $O H^{*}$ was widely distributed in the chamber during the whole combustion process, concluding that $O H^{*}$ was recognized as the most important radical that marked premixed combustions.

Iijima and Shoji [9] also performed a spectroscopic analysis of HCCI combustion for $n$-heptane and iso-octane in a 2-stroke single-cylinder engine. The authors found that the time of the peak light emission intensity in a wavelength range of 300 - $500 \mathrm{~nm}$ nearly coincides with the time of the peak 
of heat release rate, which could be used as a tracer of the high temperature ignition delay. However, no light emission spectrum attributable to cool flames was observed at high EGR rates. Moreover, a strong and long-lived light emission attributable to the $O H^{*}$ radical can be seen only under high equivalence ratios.

Kim et al. 10] compared the HCCI mode with PCCI and standard spark ignition (SI) using spectrum analysis, with a transparent engine. The authors found that the $\mathrm{CO}-\mathrm{O}^{*}$ emission dominates the spectra in the HCCI chemiluminescence emission, but it is difficult to measure $O H^{*}, C H^{*}$, and $\mathrm{C}_{2}{ }^{*}$ radicals. Moreover, the presence of $O H^{*}$ peaks in the spectra of very lean HCCI combustion could be an indication of non-homogeneous conditions. The authors concluded that chemiluminescence is as a good method for analyzing engine combustion.

Murase et al. [11 have studied the HCCI combustion with a Rapid Compression Machine by means of direct visualization and spectroscopy. They could see that during the main heat release duration the distinct $O H^{*}$ emission appeared, and it was superimposed on the carbon monoxide oxidation continuum. After the main heat release, the broad peak of the spectrum was shifted to the longer-wavelength side $\left(\mathrm{H}_{2} \mathrm{O}\right.$ vibration-rotation bands at $580.7-966.9 \mathrm{~nm})$.

Finally, Hwang et al. [12] studied the temporal phases of autoignition and combustion in an HCCI optical engine for several fuels by applying a spectroscopic and a chemical-kinetic analysis. The authors divide the combustion process in four different stages, which can be described by spectroscopy: Low-temperature heat-release phase or cool flames (only existing 
in two-stage ignition process), intermediate-temperature heat-release phase (which affects the fuel ignition quality), main high-temperature heat-release phase and, finally, a burnout phase (with very weak uniform emission and near-zero heat-release rate).

The motivation of this study is the analysis of the combustion under HCCI conditions in order to extend the aforementioned studies. The spectra of homogeneous combustions is now analysed under a wider range of conditions, extending the studies of Iijima and Shoji [9] to different equivalence ratios, compression ratios, initial temperatures and pressures and EGR rates. The importance of studying the combustion ignition delay time under HCCI conditions is justified by the role of this parameter in controlling the heat release rate and the efficiency under such conditions. The optical analysis contributes by studying the sources of the radiation and which chemical reactions control them. Furthermore, a more complete sub-model of excited $O H$ has been validated with experimental results, not only referred to the ignition delay time of $O H^{*}$ but also the time of life of the radicals. This sub-model has been developed based on the Hall and Petersen sub-model for the $O H^{*}$ [13], extending the number of reactions involved. The validation of such sub-model in a broad range of operating conditions allows the use of the mechanism in future works of research.

In this study autoignition and combustion are studied under HCCI conditions in a Rapid Compression Expansion Machine (RCEM) by means of spectroscopy. The study has been performed with two different surrogate fuels with reactivities typical of diesel fuel and gasoline: $n$-heptane and isooctane, respectively. Despite the fact that more sophisticated surrogate fuels 
for diesel and gasoline can be found in the literature, $n$-heptane and isooctane were chosen because extended and fully validated chemical kinetic mechanisms are available for both of them. Moreover, $n$-heptane, iso-octane and their blends are Primary Reference Fuels (PRF) employed to define the octane reference scale and they are widely used in the literature as surrogates of diesel and gasoline under engine conditions [14].

Spectra of the combustion process and chemiluminescent intensity distribution will be experimentally obtained under different conditions of pressure, temperature, equivalence ratio and oxygen mass fraction. Experiments are reproduced with the software of chemical simulation CHEMKIN. This software, which is developed by Reaction Design (ANSYS), is consolidated in the world of engineering investigations [15] and the chemical kinetics mechanisms of several hydrocarbons are perfectly defined to be used with it [16]. Finally, the numerical results are validated experimentally using a RCEM.

The structure of the paper is as follows:

- The experimental facilities involved in the study are presented, including the RCEM and the additional optical setup.

- The methodological approach is detailed, where the experimental and simulation methods are described and the parametric study performed is presented.

- The main chemical kinetic mechanism and the sub-model for the excited $O H$ at an excited estate are presented and validated by comparison with experimental results.

- Results are presented from a spectroscopy point of view, linking the 
optical results with different stages of the process.

- Finally, the conclusions of this study are shown.

\section{Experimental tools}

\subsection{Rapid Compression Expansion Machine}

A RCEM is an experimental facility widely used in autoignition studies due to its capability to reproduce engine conditions [17]. It can replicate the combustion process of reciprocating engines with fully controlled initial and boundary conditions and avoiding the complexities associated to engines [18].

Different compression ratios can be achieved in the RCEM by varying the stroke and the clearance volume. Axial optical access is available [19] and the compression velocity can be varied in order to simulate the effect of different engine speeds. In a RCEM part of the expansion stroke of the piston can be also analyzed and most of the engine parameters can be calculated, such as the heat release rate or the combustion efficiency. In this facility both homogeneous and heterogeneous (direct injection) mixtures can be tested, as well as new combustion modes such as the dual fuel technology [20] or LTC [21].

A schematic of the RCEM is shown in Figure 1. The RCEM is pneumatically driven and its pistons are hydraulically coupled. As it can be seen, it can be divided in two different zones, the experimentation zone and the driving zone. The experimentation zone is composed by the combustion chamber, while the driving zone is composed by four different pistons. Piston 1, which

is called pushing piston, is pneumatically driven and hydraulically coupled 
to piston 2, which is called driver piston and is directly connected with the combustion chamber. Piston 3 is hydraulically driven and it can be adjusted to select the compression stroke. Finally, piston 4 contains the compressed air that drives the machine. Details on the operation principle of the RCEM can be found in $[22]$.

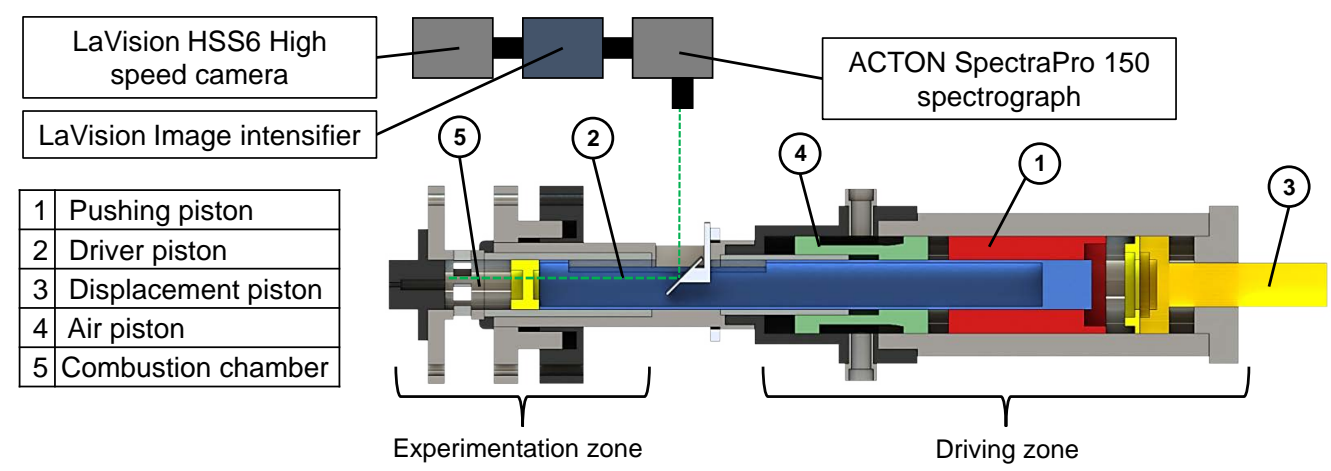

Figure 1: Rapid Compression Expansion Machine schematic.

The technical characteristics of the RCEM can be seen in Table 1. The pushing piston and the driver piston are instrumented with two incremental position sensors (AMO LMK102) with a resolution of $0.01 \mathrm{~mm}$, which allow knowing the absolute position of each piston and; therefore, the combustion chamber volume. The combustion chamber is composed by three elements, the experimentation piston (mechanically connected to the driver piston), the liner and the cylinder head. The experimentation piston consists on a steelmade piston with $84 \mathrm{~mm}$ of bore and a quartz-made bowl with cylindrical shape, $50 \mathrm{~mm}$ of bore and $2.2 \mathrm{~mm}$ of depth, which allows the axial optical access. As the bowl is flat, the chamber images can be recorded without any 
image distortion.

\begin{tabular}{|l|rl|}
\hline Bore & 84 & $\mathrm{~mm}$ \\
\hline Stroke & $120-249$ & $\mathrm{~mm}$ \\
\hline Compression ratio & $5-30$ & $: 1$ \\
\hline Maximum cylinder pressure & 200 & bar \\
\hline Initial pressure & $1-5$ & bar \\
\hline Maximum heating temperature & 473 & $K$ \\
\hline
\end{tabular}

Table 1: Technical characteristics of the RCEM.

Besides, the cylinder head and the cylinder liner have different heating elements arranged in six separately controlled zones, which are responsible for heating the cylinder walls and the experimentation piston. The wall temperature is measured by a total of six type $\mathrm{K}$ thermocouples, two located in the cylinder head and four in the liner. Very good temperature homogeneity has been observed [22], with a standard deviation of the gas temperature in the order of $3 \mathrm{~K}$. It was found that the distribution of temperature is barely affected by the gas in-flow due to its slow speed. An initial gas temperature equal to the wall temperature is achieved due to the long duration of the intake process.

The cylinder head is instrumented with a Kistler 7061B cooled piezoelectric pressure sensor (-80 $p C$ /bar of sensitivity), which is coupled to a Kistler 5011 charge amplifier, and whereby the in-cylinder pressure is measured. Different piezo-resistive pressure sensors are available to control the filling of the driving gas and of the combustion chamber (0.01 bar of resolution). The 
injection system is composed by a Siemens hollow cone piezo-injector with a cone angle of $90^{\circ}$, which is centered in the cylinder head. Its fuel delivery rate has been previously measured with an IAV injection rate analyzer. The transient signals have been recorder at $100 \mathrm{kHz}$ with a PC-based transient measurement recorder. The RCEM is filled from an external tank that can be heated up to $373 K$. The synthetic air is produced in the tank by a filling based on partial pressures where $\mathrm{N}_{2}, \mathrm{CO}_{2}$ and $\mathrm{O}_{2}$ can be used. The mixture is analyzed in a Horiba PG-250 portable gas analyzer in order to know the exact composition and ensure the correct reproduction of the experiments in CHEMKIN.

\subsection{Optical setup}

A schematic of the optical arrangement is shown in Figure 1. Passive spectroscopy measurements were performed with an Acton SpectraPro150 spectrograph (grating: $150 \mathrm{~g} / \mathrm{mm}$, blaze wavelength: $500 \mathrm{~nm}$ ) coupled with a 12-bit LaVision HighSpeedStar 6 camera and a LaVision HighSpeed IRO intensifier. The spectrograph has been pointed directly at the mirror inside the machine, which due to its $45^{\circ}$ tilt gives a direct view of the combustion chamber through the piston window. Because of the transient nature of the combustion, an acquisition frequency of $67.5 \mathrm{kHz}$ has been chosen in order to capture the evolution of the spectra inside de combustion chamber. An exposure time of $14.5 \mu \mathrm{s}$ and a rectangular image of $1024 \times 80$ pixels were selected. The whole system was calibrated by the use of an Acton MS-416 mercury lamp.

Finally, natural chemiluminescence results have been used in order to analyze the combustion process. Such results were obtained coupling a 12- 
bit LaVision HighSpeedStar6 camera with a LaVision HighSpeed IRO intensifier (acquisition frequency: $30 \mathrm{kHz}$, exposure time: $33 \mu \mathrm{s}$, resolution $384 \times 448$ pixels). A $310 \mathrm{~nm}$ interference filter $(\mathrm{FWHM}=10 \mathrm{~nm}$ ) was used to eliminate any additional radiation outside the $O H^{*}$ radical wavelength.

The transient pressure and piston position along with control and synchronization signals (i.e. camera triggers) have been recorder at $100 \mathrm{kHz}$ with a PC-based transient measurement recorder.

\section{Methodological approach}

\subsection{Rapid Compression Expansion Machine}

The desired stroke of the machine is selected and the RCEM is heated up to the desired temperature. Then, the synthetic air-EGR mixture is prepared in the mixing tank. In this study, EGR was considered as a combination of $20 \% \mathrm{CO}_{2}+80 \% \mathrm{~N}_{2}$ in volume, and it is mixed with dry air until the amount of oxygen in the mixture is the one desired by the user.

The combustion chamber is scavenged several times before the filling. The fuel is injected into the combustion chamber at the start of the intake process to avoid problems of stratification or other inhomogeneities. The long duration of the process (approximately $40 \mathrm{~s}$ ), are enough to guarantee a homogeneous environment in the chamber when the compression stroke starts.

In order to ensure a representative ignition delay time measurement the number of repetitions of each point has been selected so that the semiamplitude of the confidence interval with a level of confidence of $95 \%$ is smaller than $1 \%$ of the mean ignition delay value. The repeatability of the 
machine has been previously studied in series of 10 repetitions under motoring conditions and under combustion conditions. The following maximum coefficients of variation have been found:

\begin{tabular}{|c|c|c|c|c|}
\hline & Max. position & Time of max. pos. & Max. pressure & Time of max. press. \\
\hline CV $[\%]$ & 0.08 & 0.27 & 1.35 & 0.10 \\
\hline
\end{tabular}

In this work the autoignition of the mixture is considered to be produced when the time derivative of the pressure signal (which will be referred as pressure rise rate or, simply, pressure rise further on) reaches a maximum. Thus, the ignition delay in the experimental facility is defined as the time between the start of the rapid compression process and the instant in which the maximum pressure rise is obtained, as can be seen in Figure 2. This way, cool flames and high temperature ignition delay can be easily distinguished in case of two-stage ignition.

Finally, the temperature profile is calculated for each experiment by applying the energy equation, since the pressure profile and the position of the piston are known. The heat losses are characterized by a model based on the Woschni correlation [23]. The calculation includes two additional models for deformations and leaks, both of them explained in [24, 25].

\subsection{Spectrography}

The spectral information has been obtained by processing the images captured with the intensifier-camera group coupled to the spectrograph. An inhouse routine developed in MATLAB has been used to calculate the spectral evolution along time. The fluctuations and noise are smoothed by averaging 
the 80 vertical pixels of each image, in this way the $2 \mathrm{D}$ image is reduced to a $1 \mathrm{D}$ vector with the intensity per each wavelength.

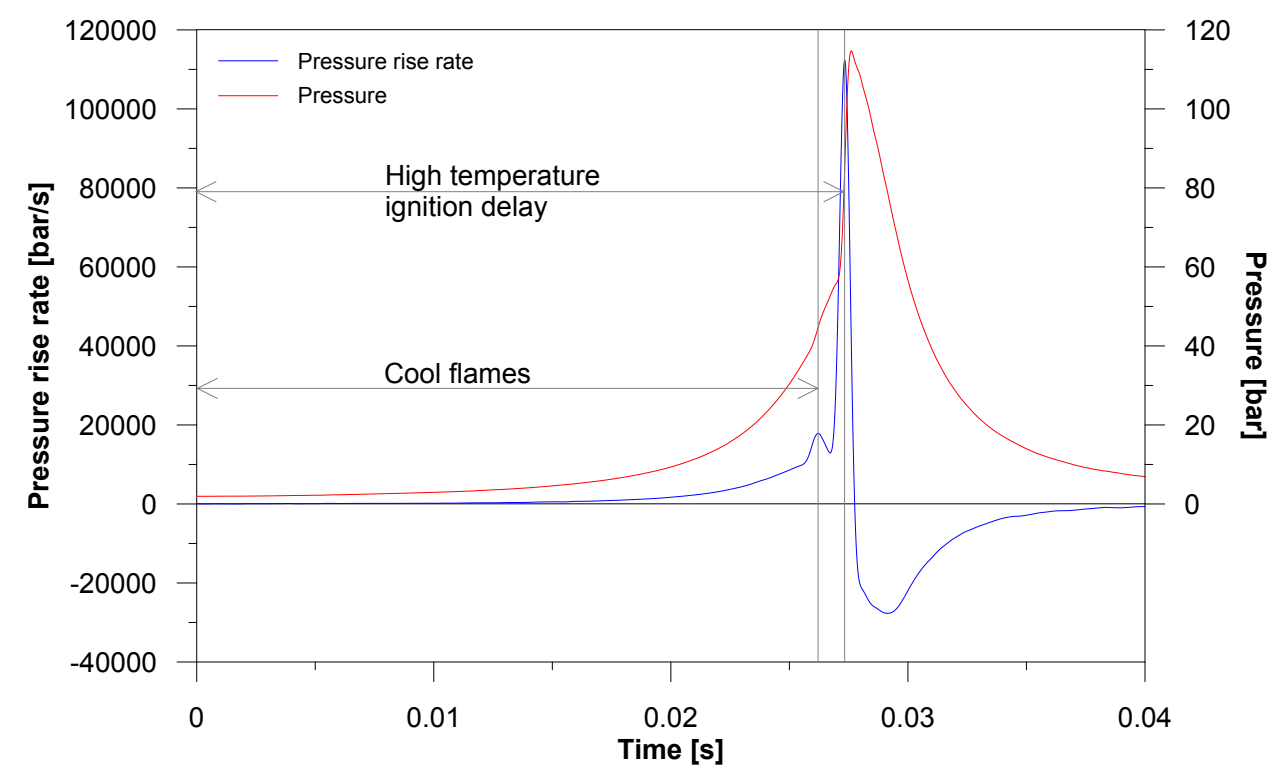

Figure 2: Ignition delay definition. The autoignition of the mixture is considered to be produced when the maximum pressure rise occurs. $n$-heptane at $C R$ 17:1, $T_{i} 358 \mathrm{~K}$, EGR $47 \%$ and $\mathrm{Fr} 0.58$.

Figure 3 shows the result of the processing routine, it can be seen that the spectral information is resolved in the horizontal axis and that the vertical one is used as a filter for noise and oscillations. Finally, what is represented in plot is the calibration of the spectrograph with a mercury lamp from which the linear relationship between pixel and wavelength is deducted with a $R^{2}$ coefficient of 1, approximately. 


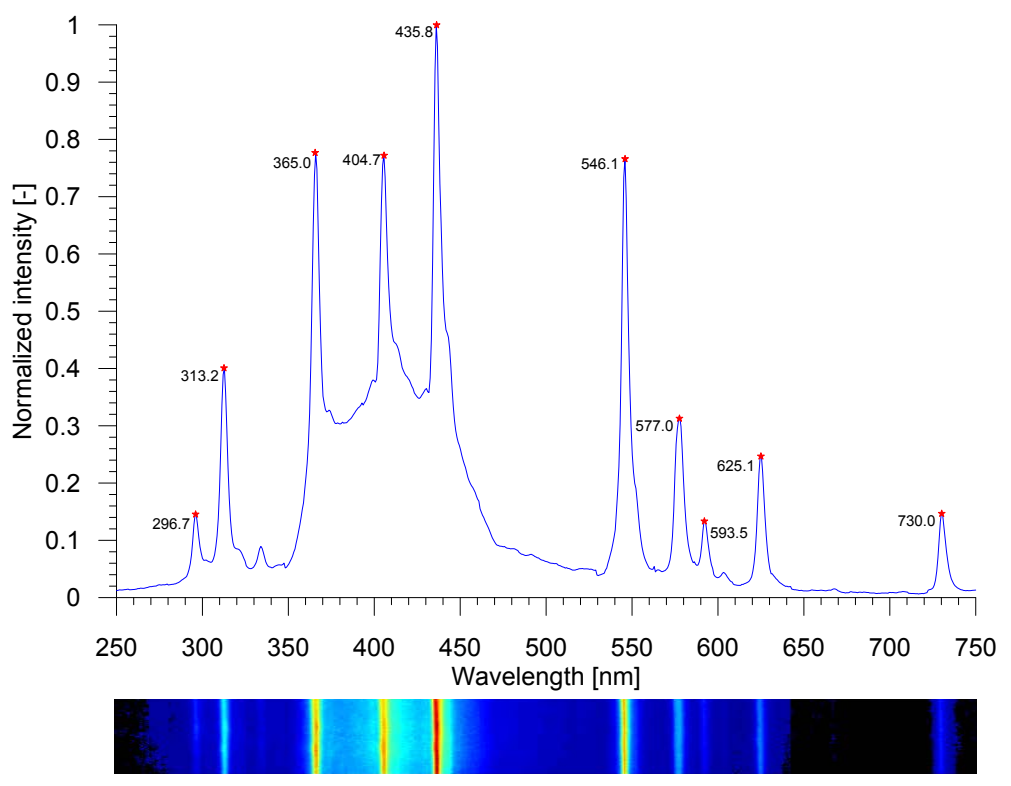

Figure 3: Spectral information of a sample image.

\subsection{Chemical kinetic mechanisms}

As previously mentioned, CHEMKIN is the software used to reproduce the experiments; the version used is CHEMKIN-PRO. Curran's kinetic mechanism is used for $n$-heptane and iso-octane [26, 27. This mechanism consists of 1034 species and 4238 reactions, and includes the chemical kinetics of the two hydrocarbons used in this investigation. Its validity has been checked in several articles by comparison with experimental results [14, 28]. Additionally, the chemical mechanism has been modified to incorporate an $O H^{*}$ sub-mechanism in order to be able to compare the chemiluminescence results in a easy way [13]. Furthermore, since the Curran chemical kinetics mechanism does not distinguish between $O H$ (ground estate) and $O H^{*}$ (excited estate) the main generation reactions of excited $O H$ have been located and 
modified in order to take into account the coexistence of both species [29]. The complete $O H^{*}$ sub-model is explained in Appendix A.

The model used to obtain ignition delay times under variable conditions is a reciprocating internal combustion engine operating with homogeneous charge (IC-engine, closed 0-D reactors from CHEMKIN). The volume profile as well as the heat loss profile are imposed in order to reproduce the RCEM conditions. The piston starts at bottom dead center (BDC) and a complete cycle of the RCEM is simulated. The autoignition is considered to be produced when the time derivative of the pressure signal reaches a maximum. This is the same criterion as the one used in the experiments, and the comparison of ignition delay times between experimental and simulated results is how the mechanism was validated. Moreover, the $\mathrm{OH}, \mathrm{OH}^{*}, \mathrm{CO}$ and $\mathrm{CO}_{2}$ concentration profiles are obtained and an analysis of their reaction rates has been performed in order to compare the simulations with the results obtained from the spectrograph. This way, the combustion phenomenon can be studied from a point of view of chemical kinetics. The maximum time step for CHEMKIN simulations has been set as $10^{-5} s$ which is the experimental resolution of the pressure signal.

\subsection{Parametric study performed}

The performed experimental study was as follows:

- Fuel: $n$-heptane and iso-octane.

- Initial temperature $\left(T_{i}\right): 358 K$ (only for n-heptane), $383 K, 408 K$, $433 K$ and $458 K$.

- Initial pressure $\left(P_{i}\right): 0.14 M P a$ and $0.17 M P a$. 
- Compression stroke: $249 \mathrm{~mm}$.

- Compression ratio $(C R): 15$ and 17 to 1 .

- Oxygen mass fraction $\left(\mathrm{Y}_{\mathrm{O}_{2}}\right): 0.23$ (0 \% EGR), 0.147 (30 \% EGR), 0.126 (40\% EGR) and 0.105 (50\% EGR).

- Equivalence ratio $(F r)$ : 0.3 to 0.8 depending on the fuel and on the oxygen mass fraction.

The expected pressure and temperature at TDC under motoring conditions for these initial operating points are summarized in Table 2 .

\begin{tabular}{|cc|cc|}
\hline \multicolumn{2}{|c|}{ CR 15:1 } & \multicolumn{2}{c|}{ CR 17:1 } \\
\hline$T_{i}[K]$ & $T_{T D C}[K]$ & $T_{i}[K]$ & $T_{T D C}[K]$ \\
\hline 358 & 874 & 358 & 911 \\
383 & 936 & 383 & 975 \\
408 & 997 & 408 & 1039 \\
433 & 1058 & 433 & 1102 \\
458 & 1119 & 458 & 1166 \\
\hline$P_{i}[M P a]$ & $P_{T D C}[M P a]$ & $P_{i}[M P a]$ & $P_{T D C}[M P a]$ \\
\hline 0.14 & 5.13 & 0.14 & 6.06 \\
0.17 & 6.23 & 0.17 & 7.36 \\
\hline
\end{tabular}

Table 2: Pressure and temperature conditions at TDC under motoring conditions for the initial operating points.

The maximum equivalence ratio is limited by the working oxygen mass fraction in order to avoid extremely violent combustions. The equivalence 
ratio of 0.4 has been chosen as the base point in order to have the possibility to try leaner and richer mixtures without damaging the facility. The performed parametric study can be seen in Table 3. Finally, the temperature of the combustion chamber is always above the boiling point of the fuel, therefore ensuring that the fuel is in vapour phase before the beginning of the cycle.

\begin{tabular}{|c|c|c|c|c|c|c|}
\multicolumn{1}{c|}{} & $\mathbf{3 5 8}$ & $\mathbf{3 8 3}$ & $\mathbf{4 0 8}$ & $\mathbf{4 3 3}$ & $\mathbf{4 5 8}$ \\
\cline { 2 - 7 } & $\mathbf{0 . 3}$ & 40 & & $0,30,40,50$ & & 40 \\
\hline $\mathbf{0 . 4}$ & $0,30,40,50$ & 40,50 & $0,30,40,50$ & 40,50 & $0,30,40,50$ \\
\cline { 2 - 7 } & $\mathbf{0 . 5}$ & 40 & 40 & 40,50 & 40 & 40 \\
\hline & $\mathbf{0 . 6}$ & 40 & & 40,50 & & 40 \\
\hline & $\mathbf{0 . 7}$ & & & 40,50 & & \\
\hline $\mathbf{0 . 8}$ & & & 40,50 & & \\
\hline
\end{tabular}

Table 3: Parametric study performed. EGR percent for different initial temperatures and equivalence ratios. Black.- common points. Blue.- exclusively for $n$-heptane. Red.exclusively for iso-octane.

\section{Chemical kinetic mechanism and $O H^{*}$ sub-model}

In this section, the validity of the chemical kinetic mechanism the submodel for the excited $O H$ at an excited estate are checked by comparing them directly with the experimental results.

\subsection{Validation of the chemical mechanism}

Ignition delay times obtained solving the $n$-heptane and iso-octane detailed chemical kinetic mechanism are compared with the experimental re- 
sults as a method to validate the mechanism in the desired range.

The percentage deviation in ignition delay $(\epsilon)$, was calculated in order to compare more easily experimental and simulation results. This deviation is defined as follows:

$$
\epsilon=\frac{t_{S O C, I C E}-t_{S O C, R C E M}}{t_{S O C, R C E M}} \times 100
$$

where $t_{S O C}$ represents the start of combustion time. The subscript $I C E$ represents a data obtained from a chemical simulation with CHEMKIN using a closed 0D ICE reactor. Finally, the subscript $R C E M$ represents a data obtained experimentally from the RCEM.

The average of the deviations in absolute value, $\bar{\epsilon}=\sum|\epsilon| / n$, has been calculated for each fuel. The confidence interval for the mean deviation with a confidence level of $95 \%$ is equal to $[1.33,1.98] \%$ for $n$-heptane and to $[1.21,1.89] \%$ for iso-octane. Ignition delay deviations are caused partly by the chemical kinetic mechanism used and partly by the uncertainties in the calculation of the effective volume and the heat losses of the RCEM. The results show that simulations are able to reproduce the experimental ignition delays with quite good accuracy.

\subsection{Validation of the $\mathrm{OH}^{*}$ sub-model}

Two additional ignition delays were defined: referred to a maximum oxidation rate of $\mathrm{CO}+\mathrm{O} \Rightarrow \mathrm{CO}_{2}+h v$, which is an estimator of the $C O$ continuum, and referred to a maximum concentration of $O H^{*}$, which is an estimator of the $O H^{*}$ chemiluminescence. Both ignition delays are obtained experimentally from the high speed camera and by simulation from CHEMKIN. The 
percentage error in the ignition delay $(\varepsilon)$, was calculated in order to compare more easily experimental and simulation results. This error is defined as follows:

$$
\varepsilon=\frac{t_{S O C x 1, I C E}-t_{S O C x 1, x 2}}{t_{S O C x 1, x 2}} \times 100
$$

where $t_{S O C x 1}$ represents the ignition delay time. The subscript $x 1$ represents one of the definitions, maximum oxidation rate of $\mathrm{CO}$ to $\mathrm{CO}_{2}$ (ignition delay referred to $\mathrm{CO}$ ) or maximum concentration of $O H^{*}$ (ignition delay referred to $\left.O H^{*}\right)$. Finally, the subscript $x 2$ represents one of the experimental methods, photo-multiplier or high-speed camera. Of course, only the cases that show $O H^{*}$ peak in the spectroscopy analysis are taken into account for the calculation of the ignition delay error referred to $O H^{*}$, and vice versa.

The average of the errors in absolute value $\left(\bar{\varepsilon}=\sum|\varepsilon| / n\right)$, has been calculated for each fuel, as well as its confidence interval with a confidence level of $95 \%$. The following results are obtained:

- Mean relative error $(\bar{\varepsilon})$ referred to $O H^{*}$, between simulations and high speed camera: $[0.581,1.725] \%$ for $n$-heptane and $[1.602,2.910] \%$ for iso-octane.

- Mean relative error $(\bar{\varepsilon})$ referred to $C O$, between simulations and high speed camera: $[1.353,2.341] \%$ for $n$-heptane and $[1.324,2.628] \%$ for iso-octane.

It is important to mention that the aforementioned errors are cause by deviation in the auto-ignition chemistry and not in the accumulation of excited $O H^{*}$. The excited $O H$ sub-model is able to predict with high accuracy 
the time at which the $O H^{*}$ is accumulated (high temperature stage of the autoignition process). Figure 4 shows the time evolution of the normalized $O H^{*}$ intensity from the high speed camera, as well as the normalized $O H^{*}$ molar fraction from CHEMKIN and the oxidation of $\mathrm{CO}$ to $\mathrm{CO}_{2}$, for two cases.
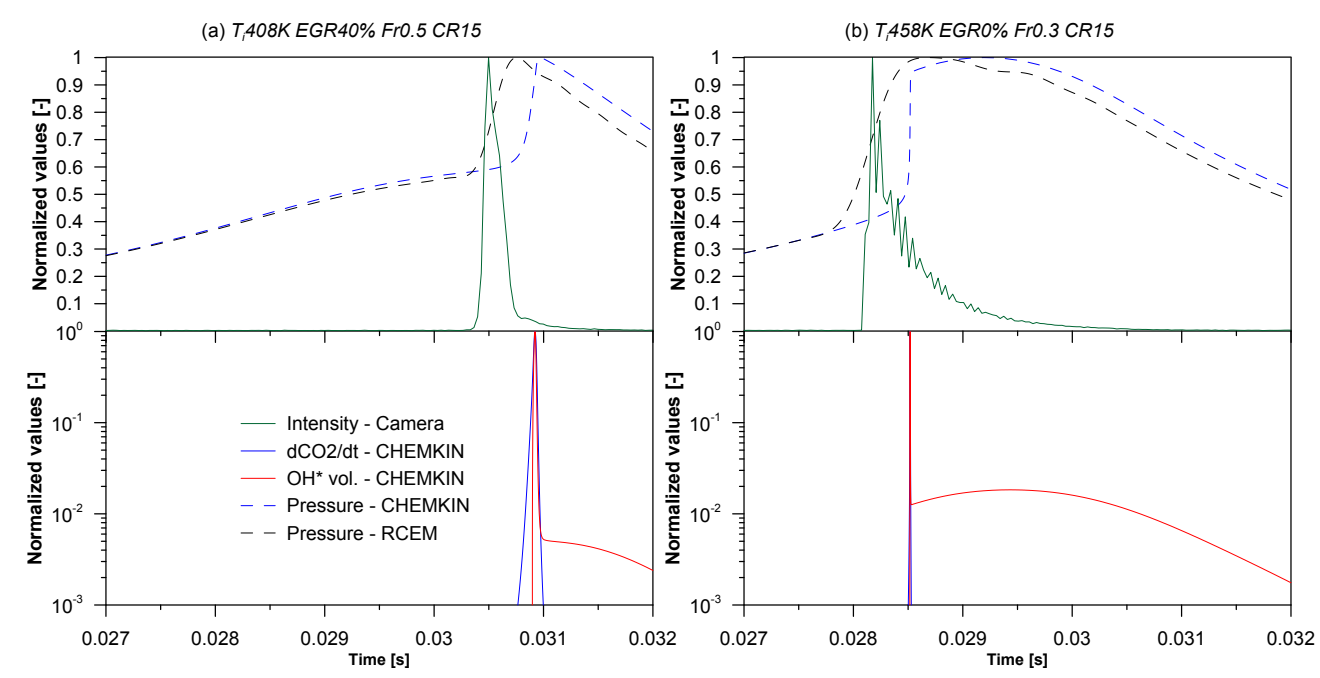

Figure 4: Normalized evolution of the oxidation rate of $\mathrm{CO}, \mathrm{OH}^{*}$ molar fraction, integrated natural chemiluminescence intensity from camera, and simulated and experimental pressures for two different cases, with and without $O H^{*}$ peak in the spectroscopic analysis. Left.- Chemiluminescence belongs to $C O$ continuum. Right.- Chemiluminescence belongs to $O H^{*}$.

Figure 4-Left shows a case in which the $O H^{*}$ radiation is outshined by the $C O$ oxidation; therefore, two different sources of radiation can be measured. On one hand, the luminosity recorded during the combustion belongs to the $C O$ continuum. On the other hand, the decay from $\approx 0.03075 \mathrm{~s}$, which occurs after the combustion, may belong to the $O H^{*}$ chemiluminescence. Figure 4 . 
Right shows a case in which the $O H^{*}$ radiation is dominant; therefore, all the chemiluminescence at $310 \mathrm{~nm}$ belongs to this radical. It should be noted that the time of life of the luminosity is much longer since the decay of the $O H^{*}$ is also gradual. The measured $O H^{*}$ radiation is consistent with the $O H^{*}$ predicted by the chemical kinetic mechanism. Both experimental methods show similar profiles, and it can be seen that a short time of life of the luminous intensity is directly related with an absence of peak of $O H^{*}$ in the spectroscopic analysis.

The $O H^{*}$ intensity is directly related with the amount of accumulated $O H^{*}$ and with the thermodynamic conditions in the combustion chamber. The higher the reached temperature and the higher the concentration of $O H^{*}$, the higher its luminous intensity. The combination of low temperature and small concentration of $\mathrm{OH}^{*}$ is the reason why cool flames are not detected by the photo-multiplier nor by the camera.

Finally, Figure 5 show a comparison between the molar fraction of $\mathrm{OH}$ at their ground and excited states for the two cases previously discussed. It can be seen that the peaks take place at the same instant for each of the cases, an instant which corresponds with the pressure rise caused by the ignition (maximum chemiluminescence). Nevertheless, the decay is different for both cases and therefore the time of life for the radiation will also be different than the $\mathrm{OH}$ at its ground estate. In this sense a sub-model for the prediction of excited $O H$ is necessary to perform a chemical kinetic analysis of chemiluminescence results. 


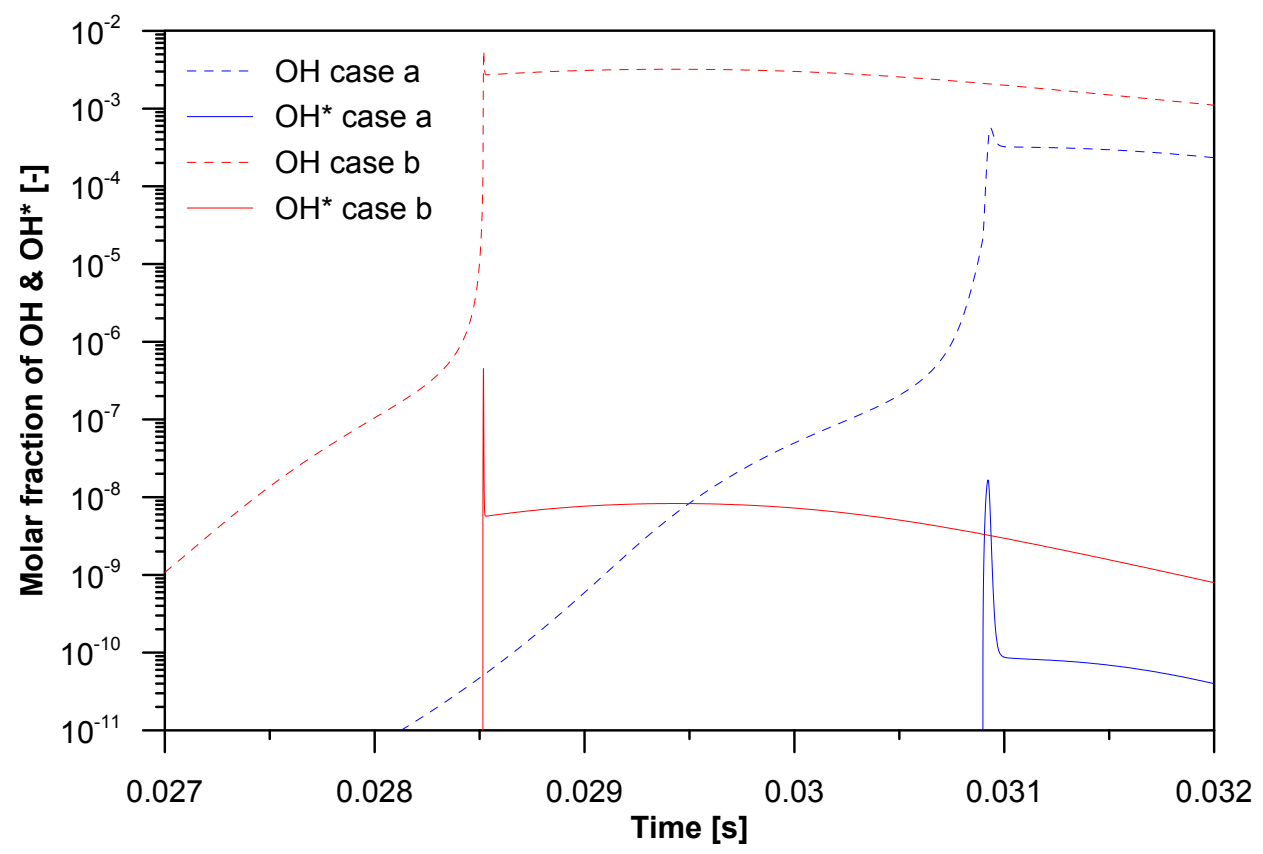

Figure 5: Molar fraction of $\mathrm{OH}$ and $\mathrm{OH}^{*}$ for the two different cases Figure 4

\section{Results and discussion}

In this section the combustion process is studied from a point of view of spectrography and chemical kinetics. After that, experimental profiles of integrated luminosity and modelled oxidation rate of $\mathrm{CO}$ and $O H^{*}$ accumulation are related.

A spectroscopic analysis was performed to determine the source of the radiation measured by natural chemiluminescence at $310 \mathrm{~nm}$. The results show two different scenarios, which can be seen in Figure 6 .

On one hand, for very lean or very low-temperature conditions the spectrum is dominated by the $C O$ continuum, which covers a range of wave- 

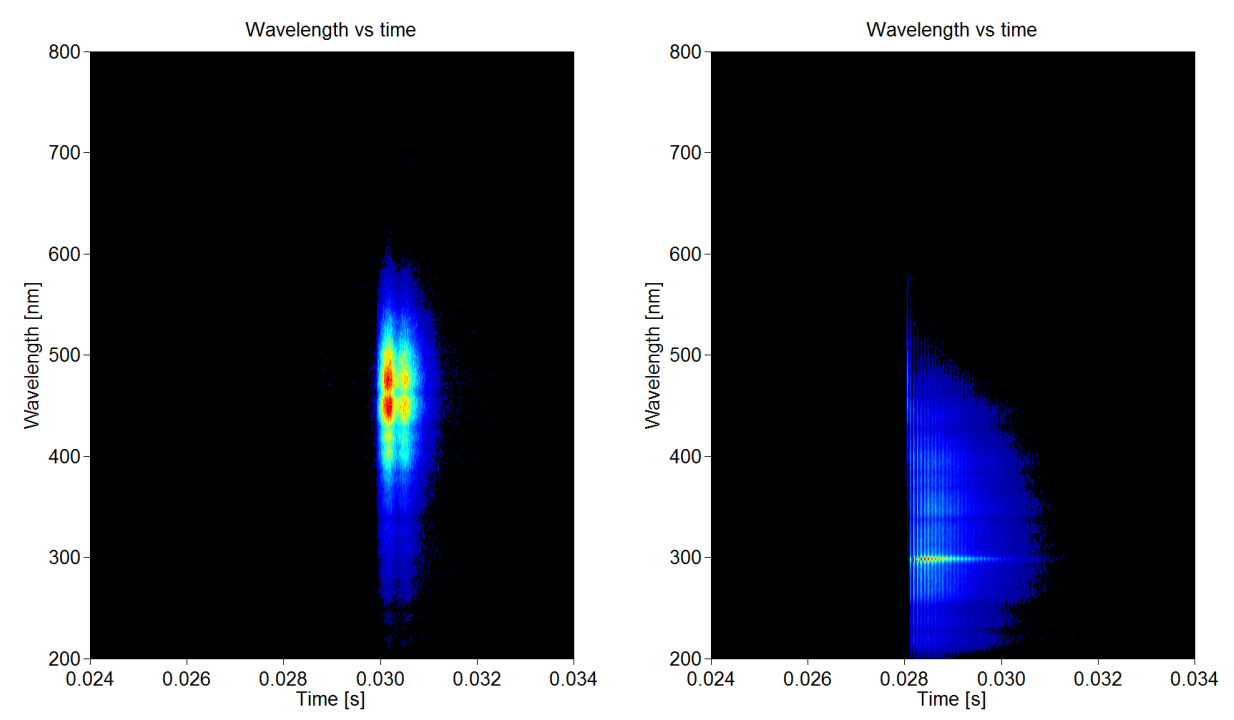

(a) $T_{i} 408 \mathrm{~K}$ EGR40 \% Fr0.5 CR15:1 (b) $T_{i} 458 \mathrm{~K}$ EGR0 \% Fr0.3 CR15:1

Figure 6: Evolution of the spectrum inside the chamber for two different cases fuelled with iso-octane. Left.- without $O H^{*}$ peak at $310 \mathrm{~nm}$. Right.- with $O H^{*}$ peak at $310 \mathrm{~nm}$.

lengths from $300 \mathrm{~nm}$ to $550 \mathrm{~nm}$. In these cases no peak of intensity can be seen around $310 \mathrm{~nm}$, which implies that the natural chemiluminescence at this wavelength belongs to the $C O$ continuum and it outshines the $O H^{*}$ radiation. On the other hand, for more intense combustions a clear and long-lasting peak of intensity centered at $310 \mathrm{~nm}$ can be identified. Thus, the natural chemiluminescence measured in these cases may belong to $O H^{*}$. Therefore, the experiments can be divided in two groups, those that present an $O H^{*}$ peak in the spectroscopic analysis and those that only show the $C O$ continuum. These groups are shown in Table 4

Figures 7 and 8 show two sequences of images where the evolution of the natural chemiluminescence at $310 \mathrm{~nm}$ over time can be seen in terms 

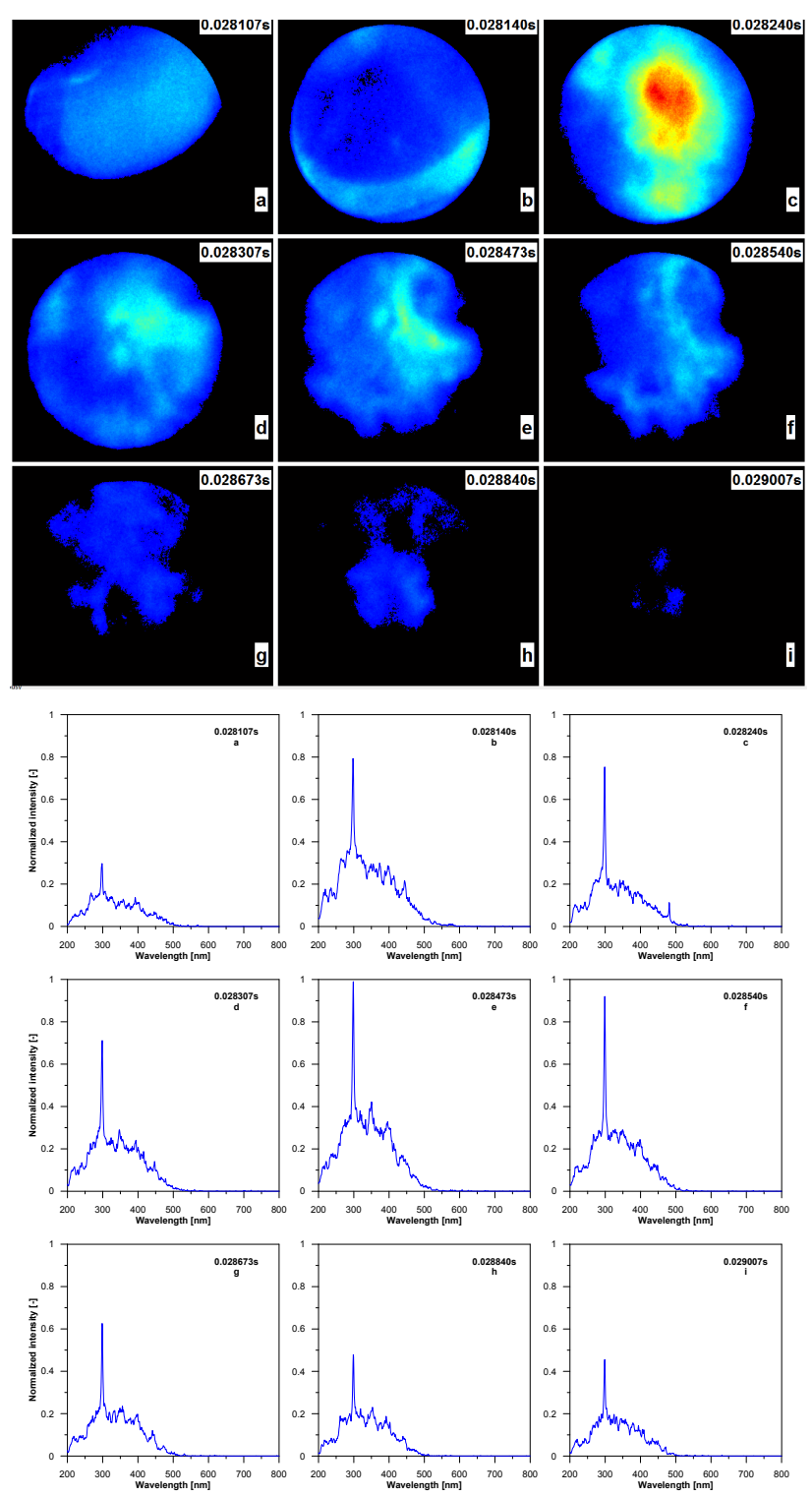

Figure 7: Evolution of chemiluminescence and spectroscopic analysis inside chamber for iso-octane at $C R$ 15:1, $T_{i} 458 K$, EGR $0 \%$ and $F r$ 0.3. Top.- $O H^{*}$ intensity. Bottom.Spectra. 

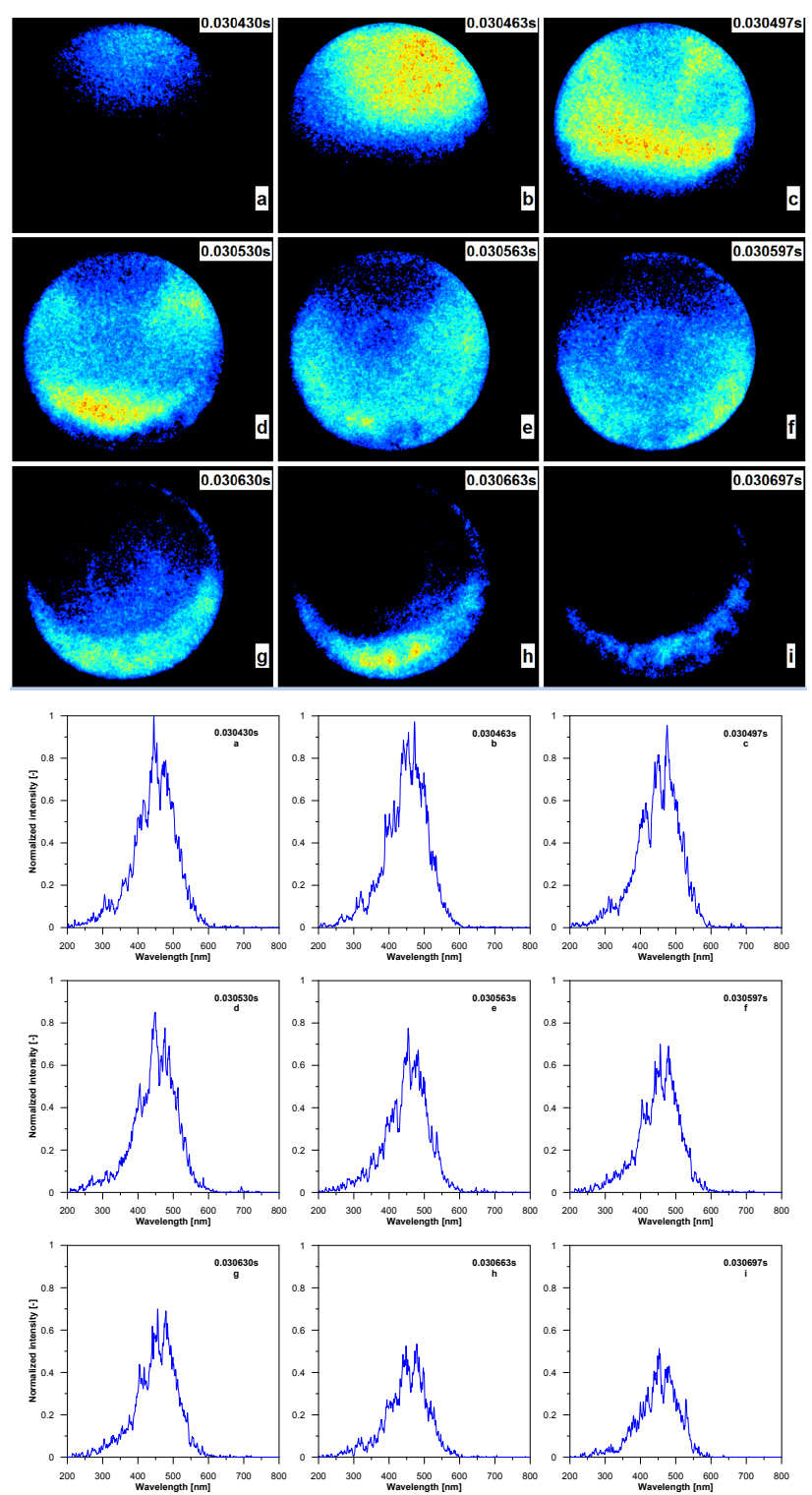

Figure 8: Evolution of chemiluminescence and spectroscopic analysis inside chamber for iso-octane at $C R$ 15:1, $T_{i} 408 K$, EGR $40 \%$ and $F r$ 0.5. Top.- $C O$ continuum intensity. Bottom.- Spectra. 


\begin{tabular}{|c|c|c|c|c|c|c|}
\multicolumn{2}{c|}{} & $\mathbf{3 5 8}$ & $\mathbf{3 8 3}$ & $\mathbf{4 0 8}$ & $\mathbf{4 3 3}$ & $\mathbf{4 5 8}$ \\
\cline { 2 - 7 } \multicolumn{1}{c|}{$\mathbf{F r}[-]$} & $\mathbf{0 . 3}$ & 40 & & $0,30,40,50$ & & 40 \\
\hline & $\mathbf{0 . 4}$ & $0,30,40,50$ & 40,50 & $0,30,40,50$ & 40,50 & $0,30,40,50$ \\
\cline { 2 - 7 } & $\mathbf{0 . 5}$ & 40 & 40 & 40,50 & 40 & 40 \\
\hline & $\mathbf{0 . 6}$ & 40 & & 40,50 & & 40 \\
\hline & $\mathbf{0 . 7}$ & & & 40,50 & & \\
\hline & $\mathbf{0 . 8}$ & & & 40,50 & & \\
\hline
\end{tabular}

Table 4: Parametric study performed. Green.- cases in which there is a peak of $O H^{*}$. Black.- cases in which the $C O$ continuum outshines the $O H^{*}$.

of intensity and area. Besides, the spectra of the combustion chamber are also showed for each time of the sequences. It can be clearly seen in Figure 7 a peak of $O H^{*}$ in the spectrum of the combustion which means that the chemiluminescent radiation measured belongs to the $O H^{*}$ radical. However, the absence of a peak in the spectrum of Figure 8 implies that the measured chemiluminescence belongs to $C O$. Additionally, by linking the information provided with Figure 4 the auto-ignition and combustion process can be described as follows:

i For two-stage ignitions, the so called cool flames start appearing and a small peak in the pressure rise rate can be seen (Figure 2). There is a tiny amount of radicals generated, which added to the low temperature are not enough to generate significant luminosity. In fact, a really small amount of $O H^{*}$ is accumulated according to the validated sub-model, being the main formation reaction of such radi- 
cal $\mathrm{HO}_{2}+\mathrm{H} \Rightarrow \mathrm{OH}+\mathrm{OH}^{*}$. However, $\mathrm{HO}_{2}$ has an accumulation behavior during cool flames and the relevance of the previous reaction is negligible. Moreover, the exited $O H^{*}$ that is formed during this stage reacts with the $\mathrm{CH}_{3}$ through the third body reaction $\mathrm{CH}_{3}+\mathrm{OH}^{*}+\mathrm{M} \Rightarrow \mathrm{CH}_{3} \mathrm{OH}+\mathrm{M}$. Therefore, no decay of exited $\mathrm{OH}$ to its ground state is present and no radiation is emitted.

ii With the start of the NTC phase there is a decrease in reactivity as the formation of chain carriers and formation of olefins are competing against each other; causing a change of slope in the pressure curve (Figure 2). Almost all the exothermic reactions are frozen during this stage, including the generation and decay of $O H^{*}$. Thus, no radiation can be seen during the NTC zone.

iii The NTC stage comes to an end due to a slight increase in temperature. This phase is controlled by the decomposition of $\mathrm{H}_{2} \mathrm{O}_{2}$ through a thirdbody reaction $\mathrm{H}_{2} \mathrm{O}_{2}+\mathrm{M} \Rightarrow 2 \mathrm{OH}+\mathrm{M}$. There is still no presence of $O H^{*}$ chemiluminescence as the $O H$ generated is consumed to oxidize formaldehyde into $\mathrm{CO}$ instead of forming excited $O H^{*}$. At this point the heat release starts.

iv After its formation, the $\mathrm{CO}$ starts to oxidize into $\mathrm{CO}_{2}$. The oxidation of $\mathrm{CO}$ is mainly caused by $\mathrm{OH}$ through $\mathrm{CO}+\mathrm{OH} \Rightarrow \mathrm{CO}_{2}+\mathrm{H}$ and by $\mathrm{O}$ through $\mathrm{CO}+\mathrm{O} \Rightarrow \mathrm{CO}_{2}+h v$ (which is a luminous reaction). Therefore, the so called $C O$ continuum starts. This light emission covers a range of wavelengths from $300 \mathrm{~nm}$ to $550 \mathrm{~nm}$ and, if it is bright enough, it can outshine the $O H^{*}$ chemiluminescence. 
At the same time, the $O H$ accumulation starts through the reactions $\mathrm{O}+\mathrm{H}_{2} \mathrm{O} \Rightarrow 2 \mathrm{OH}$ and $\mathrm{H}+\mathrm{O}_{2} \Rightarrow \mathrm{O}+\mathrm{OH}$. The appearance of excited $O H^{*}$ is promoted by the accumulation of $O H$ and the chemiluminescence radiation starts. Light is emitted by the decay of $O H^{*}$ to its ground state mainly thanks to its reaction with $\mathrm{O}_{2}, \mathrm{CO}, \mathrm{CO}_{2}, \mathrm{H}_{2} \mathrm{O}$ and $\mathrm{N}_{2}\left(O H^{*}+M \Rightarrow O H+M\right)$. H2O is the dominant third body species whereas N2 is the less relevant due to the higher activation energy of its reaction. At the end of this phase the pressure rise rate reaches a peak (Figure 4) and it is in this instant where the chemiluminescence takes up the whole chamber (Figures 7 -c and 8-c).

Two different scenarios can be present at this stage. For lean equivalence ratios or low-temperature conditions the accumulated $O H^{*}$ is not enough and the natural chemiluminescence at $310 \mathrm{~nm}$ belongs to the $C O$ continuum, since no peak can be seen at this wavelength (Figure 8 . Bottom). However, for higher combustion temperatures the active compound $H$ formed during the oxidation of $C O$ terminates with the radical $\mathrm{HO}_{2}$ (last chain carrier to disappear) through $\mathrm{H}+\mathrm{HO}_{2} \Rightarrow 2 \mathrm{OH}$. The increase of relevance of this reaction at high combustion temperatures causes a higher $O H^{*}$ accumulation, which leads to a brighter $O H^{*}$ emission. In this case, a peak of intensity can be seen at $310 \mathrm{~nm}$ (Figure 7-Bottom), which means that the natural chemiluminescence at this wavelength belongs to $O H^{*}$.

v Once all the $\mathrm{CO}$ has been oxidized into $\mathrm{CO}_{2}$ the maximum cycle pressure is reached and the heat release stops (Figure 4). For the cases in which the $C O$ continuum predominates, this instant coincides with 
the end of the light emission (Figure 8-i). However, for the cases that show peak of $O H^{*}$, significant amounts of this radical remains in the combustion chamber and the luminous intensity continues during part of the expansion (Figure 7 -h).

vi Finally, the excited $O H^{*}$ disappears and the chemiluminescence of $O H$ stops. Since the $O H$ radical is only stable at high temperatures, it also disappears during the expansion stroke (Figure 7 -i) by its recombination with atomic oxygen, $\mathrm{OH}+\mathrm{O} \Rightarrow \mathrm{O}_{2}+\mathrm{H}$.

The oxidation of $\mathrm{CO}$ and the accumulation of $O H^{*}$ occur simultaneously. Therefore, a priori, it is not possible to decide without a spectrograph if the natural chemiluminescence at $310 \mathrm{~nm}$ belongs to $O H^{*}$ or if it is outshined by the $C O$ continuum. However, it should be noted that the time of life of the luminous intensity is very different in case of belonging to $C O$ continuum or to $O H^{*}$, as can be seen in Figure 4, where the time of life of the $O H^{*}$ chemiluminescence is $0.65 \mathrm{~ms}$ longer than the $C O$ continuum luminosity. Thus, it is possible to use this parameter as a criterion to determine the source of the radiation.

\section{Conclusions}

The auto-ignition process and phases of combustion under HCCI combustion conditions using PRFs have been studied in a RCEM by means spectroscopy. The experimental results have also been used to validate a chemical kinetic mechanism for $n$-heptane and iso-octane and a sub-model for the excited $O H$. Additionally, the different combustion phases have been 
analyzed by measuring the chemiluminescence of $O H^{*}$ and $C O$ and the results have been contrasted with those of the chemical kinetics. Last, the experimental results of radiation have also been related to the simulations.

The following conclusions can be deducted from this study:

- The experimental ignition delay times have been reproduced with the chemical kinetic mechanism. Additionally, the different definitions of ignition delay are able to be reproduce, such as: Maximum pressure rise, maximum concentration of $\mathrm{OH}$, and maximum oxidation rate of CO.

- The spectroscopic analysis showed that there were two types of emission; one dominated by the $C O$ continuum and another from the $O H^{*}$. The $C O$ was seen to appear at lean equivalence ratios and low temperatures, while on the other hand, the $O H^{*}$ was present at high combustion temperatures. Reaction $\mathrm{H}+\mathrm{HO}_{2} \Rightarrow 2 \mathrm{OH}$ becomes more relevant at high combustion temperatures, which causes high accumulation of $\mathrm{OH}^{*}$ and therefore higher luminosity. Additionally, the fuel also showed a big influence on the type of luminosity generated. The cases with iso-octane presented a more violent combustion which lead to the generation of more $O H^{*}$, whereas the luminous emission from cases with $n$-heptane was more prone to be dominated by the $C O$ continuum. Therefore, the cases can be separated into two groups $\left(O H^{*}\right.$ and $C O$ ) based on the contour conditions and fuel employed.

- Neither of the optical techniques applied (chemiluminescence nor spectroscopy) were able to detect the cool flames. This was because either 
the in-cylinder temperature was too low or the the accumulated $O H^{*}$ concentration was too little. The luminous intensity of the $O H^{*}$ radical started when the $\mathrm{CO}$ began oxidizing into $\mathrm{CO}_{2}$, before the generated $\mathrm{OH}$ was consumed by the generation of $\mathrm{CO}$. The time of maximum pressure rise rate was coincidental with that of the the maximum radiation, which also took place very close to the maximum oxidation rate of the $\mathrm{CO}$ to $\mathrm{CO}_{2}$. And last, $\mathrm{OH}^{*}$ radical disappeared during the expansion stroke as it was only stable at high temperatures.

- Separating the chemiluminescence emitted by the accumulation of the $\mathrm{OH}^{*}$ radical from that coming from the oxidation of $\mathrm{CO}$ to $\mathrm{CO}_{2}$ was a difficult task to accomplish just by using natural chemiluminescence measurements at $310 \mathrm{~nm}$. However, given the different time of life of each of the species, where that corresponding the $C O$ is shorter than the one of $\mathrm{OH}^{*}$, it was found that the time of life was an appropriate indicator of the origin of the luminosity detected being longer for the cases in which the $O H^{*}$ dominates the radiation. 


\section{Acknowledgements}

The authors would like to thank different members of the LAV team of the ETH-Zürich for their contribution to this work. The authors are grateful to the Universitat Politècnica de València for financing the Ph.D. Studies of W.Vera-Tudela (FPI SP1 grant 30/05/2012) and his stay at ETH-Zürich (grant 30/12/2014). Finally, the authors would like to thank the Spanish Ministry of Education for financing the Ph.D. Studies of Darío López-Pintor (grant FPU13/02329) and his stay at ETH-Zürich (grant EST14/00626).

\section{Nomenclature}

$\begin{array}{ll}\text { Abbreviations } \\ B D C & \text { Bottom dead center } \\ C I & \text { Compression ignition } \\ C R & \text { Compression ratio } \\ E G R & \text { Exhaust gas recirculation } \\ F W H M & \text { Full width at half maximum } \\ H C C I & \text { Homogeneous charge compression ignition } \\ I C E & \text { Referred to data obtained from CHEMKIN using the internal com- } \\ & \text { bustion engine reactor } \\ L T C & \text { Low temperature combustion } \\ N T C & \text { Negative temperature coefficient } \\ P C C I & \text { Premixed charge compression ignition } \\ P H M & \text { Photo-multiplier } \\ P R F & \text { Primary reference fuel } \\ R C E M & \text { Rapid compression expansion machine } \\ S I & \text { Spark ignition }\end{array}$


TDC Top dead center

UHC Unburned hydrocarbons

\section{Greek letters}

$\epsilon \quad$ Percentage error in ignition delay referred to the maximum pressure rise between experimental and simulation results

$\bar{\epsilon} \quad$ Mean relative error in ignition delay referred to the maximum pressure rise between experimental and simulation results

$\varepsilon \quad$ Percentage error in ignition delay referred to the peak of $O H^{*}$ or maximum oxidation rate of $C O$ between experimental and simulation results

$\bar{\varepsilon} \quad$ Mean relative error in ignition delay referred to the peak of $O H^{*}$ or maximum oxidation rate of $C O$ between experimental and simulation results

\section{Roman letters}

$P \quad$ Air pressure

$T \quad$ Air temperature

$t \quad$ Time

Fr Working equivalence ratio

$Y \quad$ Mass fraction

\section{Subscripts}

$i \quad$ corresponding to the initial conditions

ICE corresponding to the simulations with CHEMKIN using a 0D ICE reactor

$\mathrm{O}_{2} \quad$ corresponding to the oxygen specie

RECEM corresponding to the experimental results from the RCEM

$S O C \quad$ corresponding to the start of combustion

TDC corresponding to the top dead center

$x 1 \quad$ corresponding to either the simulated maximum oxidation rate of $C O$ to $\mathrm{CO}_{2}$ or maximum concentration of $\mathrm{OH}^{*}$ 
Superscripts

* $\quad$ corresponding to the excited state of an element

\section{Appendix A. Excited OH sub-model}

The excited $\mathrm{OH}$ sub-model is composed by two blocks of reactions. On one hand, some reactions of the Curran chemical kinetics mechanism have been modified in in order to distinguish the ground state $O H$ from the excited state one $\left(O H^{*}\right)$ maintaining the same specific reaction rates of the original mechanism [26, 27]. On the other hand, the Hall and Petersen sub-model for the $O H^{*}$ has been taken into account. The specific reaction rate of each reaction can be found in the corresponding reference [13. All 22 reactions where the $O H^{*}$ is involved are shown below. 


\begin{tabular}{|c|c|}
\hline & Reaction \\
\hline 1 & $\mathrm{CH}+\mathrm{O}_{2} \Leftrightarrow \mathrm{CO}+\mathrm{OH}^{*}$ \\
\hline 2 & $H+O+M \Leftrightarrow O H^{*}+M$ \\
\hline 3 & $\mathrm{H}+2 \mathrm{OH} \Leftrightarrow \mathrm{OH}^{*}+\mathrm{H}_{2} \mathrm{O}$ \\
\hline 4 & $O H^{*}+A r \Leftrightarrow O H+A r$ \\
\hline 5 & $O H^{*}+H_{2} O \Leftrightarrow O H+H_{2} O$ \\
\hline 6 & $\mathrm{OH}^{*}+\mathrm{CO}_{2} \Leftrightarrow \mathrm{OH}+\mathrm{CO}_{2}$ \\
\hline 7 & $O H^{*}+C O \Leftrightarrow O H+C O$ \\
\hline 8 & $O H^{*}+H \Leftrightarrow O H+H$ \\
\hline 9 & $O H^{*}+H_{2} \Leftrightarrow O H+H_{2}$ \\
\hline 10 & $O H^{*}+O_{2} \Leftrightarrow O H+O_{2}$ \\
\hline 11 & $O H^{*}+O \Leftrightarrow O H+O$ \\
\hline 12 & $O H^{*}+O H \Leftrightarrow O H+O H$ \\
\hline 13 & $\mathrm{OH}^{*}+\mathrm{CH}_{4} \Leftrightarrow \mathrm{OH}+\mathrm{CH}_{4}$ \\
\hline 14 & $O H^{*}+N_{2} \Leftrightarrow O H+N_{2}$ \\
\hline 15 & $O H^{*} \Leftrightarrow O H+h v$ \\
\hline 16 & $\mathrm{CH}_{4}+\mathrm{O} \Leftrightarrow \mathrm{CH}_{3}+\mathrm{OH}^{*}$ \\
\hline 17 & $O+H_{2} \Leftrightarrow H+O H^{*}$ \\
\hline 18 & $\mathrm{O}+\mathrm{H}_{2} \mathrm{O} \Leftrightarrow \mathrm{OH}+\mathrm{OH}^{*}$ \\
\hline 19 & $\mathrm{CH}_{3} \mathrm{OH}+\mathrm{M} \Leftrightarrow \mathrm{CH}_{3}+\mathrm{OH}^{*}+\mathrm{M}$ \\
\hline 20 & $\mathrm{NH}_{3}+\mathrm{O} \Leftrightarrow \mathrm{NH}_{2}+O \mathrm{H}^{*}$ \\
\hline 21 & $H O_{2}+O \Leftrightarrow O H^{*}+O_{2}$ \\
\hline 22 & $\mathrm{HO}_{2}+\mathrm{H} \Leftrightarrow \mathrm{OH}+\mathrm{OH}^{*}$ \\
\hline
\end{tabular}

\section{References}

[1] N.P. Komninos. The effect of thermal stratification on HCCI combustion: A numerical investigation. Applied Energy, 139:291-302, 2015.

[2] J. Rezaei, M. Shahbakhti, B. Bahri, and A.A. Aziz. Performance prediction of HCCI engines with oxygenated fuels using artificial neural networks. Applied Energy, 138:460-473, 2015. 
[3] A.P. Singh and A.K. Agarwal. Combustion characteristics of diesel HCCI engine: An experimental investigation using external mixture formation technique. Applied Energy, 99:116-125, 2012.

[4] C. Fang, F. Yang, M. Ouyang, G. Gao, and L. Chen. Combustion mode switching control in a HCCI diesel engine. Applied Energy, 110:190-200, 2013.

[5] D. Jung and N. Iida. Closed-loop control of HCCI combustion for DME using external EGR and rebreathed EGR to reduce pressure-rise rate with combustion-phasing retard. Applied Energy, 138:315-330, 2015.

[6] R. Augusta, D.E. Foster, J.B. Ghandhi, J. Eng, and P.M. Najt. Chemiluminescence measurements of homogeneous charge compression ignition (HCCI) combustion. In SAE Technical Papers, editor, 2006 SAE World Congress, Detroit, MI; United States, 3 2006. Code 90162.

[7] H.F. Liu, M.F. Yao, C. Jin, P. Zhang, Z.M. Li, and Z.Q. Zheng. Chemiluminescence spectroscopic analysis of homogeneous charge compression ignition combustion processes. Spectroscopy and Spectral Analysis, 30:2611-2615, 2010.

[8] E. Mancaruso and B.M. Vaglieco. Spectroscopic measurements of premixed combustion in diesel engine. Fuel, 90:511-520, 2011.

[9] ASME-JSME, editor. A spectroscopic analysis of combustion in homogeneous charge compression ignition engine, Vancouver, British Columbia, CANADA, 72007. ASME-JSME Thermal Engineering Summer Heat Transfer Conference. HT200732552 .

[10] B. Kim, M. Kaneko, Y. Ikeda, and T. Nakajima. Detailed spectral analysis of the process of HCCI combustion. Proceedings of the Combustion Institute, 29:671-677, 2002.

[11] E. Murase, K. Hanada, T. Miyaura, and J. Ikeda. Photographic observation and emission spectral analysis of homogeneous charge compression ignition combustion. Combustion Science and Technology, 177:1699-1723, 2005. 
[12] W. Hwang, J. Dec, and M. Sjï $\frac{1}{2}$ berg. Spectroscopic and chemical-kinetic analysis of the phases of HCCI autoignition and combustion for single- and two-stage ignition fuels. Combustion and Flame, 154:387-409, 2008.

[13] J.M. Hall and E.L. Petersen. An optimized kinetics model for $\mathrm{OH}$ chemiluminescence at high temperatures and atmospheric pressures. International Journal of Chemical Kinetics, 38:714-724, 2006.

[14] M. Sjoberg and J.E. Dec. Isolating the effects of fuel chemistry on combustion phasing in an HCCI engine and the potential of fuel stratification for ignition control. SAE Technical Paper, 2004-01-0557, 2004.

[15] J. M. Desantes, J. J. López, S. Molina, and D. López-Pintor. Numerical simulation of autoignition of gasoline-ethanol/air mixtures under different conditions of pressure, temperature, dilution, and equivalence ratio. SAE Technical Paper, 2011-01-0341, 2011.

[16] J. M. Desantes, J. J. López, S. Molina, and D. López-Pintor. Validity of the livengood $\&$ wu correlation and theoretical development of an alternative procedure to predict ignition delays under variable thermodynamic conditions. Energy Conversion and Management, 105:836-847, 2015.

[17] D. Mitakos, C. Blomberg, Y. Wright, P. Obrecht, B. Schneider, and K. Boulouchos. Integration of a cool-flame heat release rate model into a 3-stage ignition model for HCCI applications and different fuels. SAE Technical Paper, 2014-01-1268, 2014.

[18] G. Barroso, A. Escher, and K. Boulouchos. Experimental and numerical investigations on HCCI combustion. SAE Technical Paper, 2005-24-038, 2005.

[19] D. Mitakos, C. Blomberg, A. Vandersickel, Y. Wright, B. Schneider, and K. Boulouchos. Ignition delays of different homogeneous fuel-air mixtures in a Rapid Compression Expansion Machine and comparison with a 3-stage-ignition model parametrized on shock tube data. SAE Technical Paper, 2013-01-2625, 2013. 
[20] S. Schlatter, B. Schneider, Y. Wright, and K. Boulouchos. Comparative study of ignition systems for lean burn gas engines in an optically accessible Rapid Compression Expansion Machine. SAE Technical Paper, 2013-24-0112, 2013.

[21] T. Steinhilber and T. Sattelmayer. The effect of water addition on HCCI diesel combustion. SAE Technical Paper, 2006-01-3321, 2006.

[22] S. Schlatter, B. Schneider, Y. Wright, and K. Boulouchos. Experimental study of ignition and combustion characteristics of a diesel pilot spray in a lean premixed methane/air charge using a Rapid Compression Expansion Machine. SAE Technical Paper, 2012-01-0825, 2012.

[23] G. Woschni. A universally applicable equation for the instantaneous heat transfer coefficient in the internal combustion engine. SAE Technical Paper, 670931, 1967.

[24] J. Benajes, P. Olmeda, J. Martï $₫ \frac{1}{2} \mathrm{n}$, and R. Carreï $\measuredangle \frac{1}{2}$ o. A new methodology for uncertainties characterization in combustion diagnosis and thermodynamic modelling. Applied Thermal Engineering, 71:389-399, 2014.

[25] F. Payri, S. Molina, J. Martï $i \frac{1}{2} \mathrm{n}$, and O. Armas. Influence of measurement errors and estimated parameters on combustion diagnosis. Applied Thermal Engineering, $26: 226-236,2006$.

[26] H.J. Curran, P. Gaffuri, Pitz W.J, and C.K. Westbrook. A comprehensive modeling study of n-heptane oxidation. Combustion and Flame, 114:149-177, 1998.

[27] H.J. Curran, P. Gaffuri, W. J. Pitz, and C. K. Westbrook. A comprehensive modeling study of iso-octane oxidation. Combustion and Flame, 129:253-280, 2002.

[28] H.J. Curran, W.J. Pitz, C.K. Westbrook, C.V. Callahan, and F.L. Dryer. Oxidation of automotive primary reference fuels at elevated pressures. Proceedings of the Combustion Institute, 27:379-387, 1998.

[29] C.H. Bamford, R.G. Compton, and C.F.H. Tipper. The Formation and Decay of Excited Species. Elsevier Science, 1 edition, 11969. 
[30] S.T. Lunt, G. Marston, and R.P. Wayne. Formation of $\mathrm{O}_{2}\left(a^{1} \Delta_{g}\right)$ and vibrational excited $O H$ in the reaction between $O$ atoms and $H O_{x}$ species. Journal of the Chemical Society, Faraday Transactions 2: Molecular and Chemical Physics, 84(7):899-912, 1988. 